\title{
Evaluation of Insecticidal and Antimicrobial Effect of Boerhavia diffusa
}

\author{
T.M. Manjima ${ }^{1}$, O.G. Indusree ${ }^{2}$, V.S. Ajitha ${ }^{3^{*}}$ \\ ${ }^{1,2,3}$ PG and Research Dept. of Zoology, University College, Thiruvananthapuram, Kerala, India-695034 \\ *Corresponding Author: ajithasooryakanth@gmail.com Tel.: +91-9495192932
}

Available online at: www.isroset.org

Received: 12/Apr/2019, Accepted: 25/Apr/2019, Online: 30/Apr/2019

\begin{abstract}
Boerhavia diffusa, commonly known as 'Punarnava' in the Indian system of medicine is a perennial creeping herb found throughout the waste lands. The insecticidal activity of aqueous and acetone extracts of $B$. diffusa was tested against the pest insect Dysdercus cingulatus, commonly known as Red Cotton Bug. The plant extract exhibited ovicidal effect, nymphicidal effect, varying degree of moulting disruption, reduced fecundity rate along with prolonged mating period. Insecticidal property exhibited by this plant extract can be exploited in the field of Integrated Pest Management, so as to reduce the hazardous effects of chemical pesticides. The toxic principles present in the plant extract are actually secondary metabolites that are evolved as a protective measure against herbivorous animals. Antimicrobial activity of $B$. diffusa was also evaluated using gram negative bacteria, Pseudomonas aeruginosa and showed significant level of sensitivity to $B$. diffusa extracts. Thus it is evident that $B$. diffusa possess toxic principles having insecticidal as well as antimicrobial activity which can be employed in the field of agriculture and medicine respectively.
\end{abstract}

Keywords - Biopesticide, Antimicrobial agent, Dysdercus cingulatus, Pseudomonas aeruginosa, Boerhavia diffusa

\section{INTRODUCTION}

Plants have the ability to synthesize a wide variety of chemical compounds that are used to perform important biological functions and to defend against attack from predators such as insects, bacteria, fungi and even herbivorous mammals. Among these phytochemicals, secondary metabolites are organic compounds which are found in a smaller range and serving a more specific function. Plants contribute a rich source of bioactive molecules which are useful alternatives to synthetic chemical pesticides in the control of insect pests. Globally greater awareness has been created on plant derived substances as they are ecofriendly and possess more insecticidal properties through multifarious functions [1].

Pathogenic bacteria have always been considered as major cause of morbidity and mortality in human. Due to increase of microbial resistance to antibiotics, there is need for developing new innovative antimicrobial agents. There is a long tradition of using dietary plants in the treatment of many infectious diseases [2].

Dysdercus cingulatus, commonly known as Red Cotton Bug is a serious pest of cotton and okra. Nymphs and adults feed on developing cotton bolls and heavy infestations affect crop mass, oil content and the marketability of the cotton crop. Cotton is the most economically important natural fiber material in the world. India has the largest area under cotton cultivation. In recent years, yield of cotton has become declining due to infestation of pest attack [3, 4]. Insecticidal potential of Boerhavia diffusa was tested against this particular pest insect.

Pseudomonas aeruginosa is a common gram-negative bacterium found in soil, water and most man-made environment, and cause disease in animals including humans. The symptoms of infections are generalized inflammation and sepsis. If such colonization occurs in critical body organs such as lungs, urinary tract, kidney, the results may be fatal [5]. P. aeruginosa is naturally resistant to a large range of antibiotics which is attributable to a concerted action of multidrug efflux pump with chromosomally encoded antibiotic resistant gene [6].Antimicrobial activity of $B$. diffusa was assessed using this microorganism.

B. diffusa commonly known as 'Punarnava' in the Indian system of medicine is a perennial creeping herb found throughout the waste lands. Plant is known to have medicinal properties and have a long history of use by indigenous and tribal people in India [7]. In Ayurvedic system of medicine, it is widely used in jaundice, oedema, anaemia, inflammation, immunomodulation, antifertility and eye diseases [8]. The important bioactive phytochemicals in this plant are glycosides, flavonoids, tannins, terpenoids, phenolic compounds etc [9]. 
In the present study, the insecticidal efficacy of acetone and aqueous extracts of Boerhavia diffusa were tested against Dysdercus cingulatus, the serious cotton pest. Boerhavia diffusa aqueous extract were used to test the antimicrobial property against the pathogenic bacterium, Pseudomonas aeruginosa. The results obtained in this study clearly demonstrate the insecticidal potential of $B$. diffusa which may find significance as a safe biopesticide against the cotton pest $D$. cingulatus, especially in the present scenario of dangerous chemical pesticides. Antimicrobial effect of this plant was also successfully proved against $P$. aeruginosa, a pathogenic bacterium, which can be exploited in medical field.

\section{METHODOLOGY}

\section{Pest collection and rearing}

Dysdercus cingulatus were collected from Kerala Forest Research Institute (KFRI) Thrissur and Vandithavalam, Palakkad District, Kerala. The collected insects were maintained in the insectory under laboratory conditions in transparent plastic containers covered with cotton cloth. Insects were fed with their natural food, cotton seeds. Before experimentation insects were maintained for 3 generations in the laboratory. 12-24 hr old fifth stadium and newly emerged adult female $D$. cingulatus were used for the experiment.

\section{Collection of plant for extract preparation}

The plant, Boerhavia diffusa was collected from different locations of Kerala and identified at Department of Botany, University College, Thiruvananthapuram, Kerala. The fresh leaves were washed thoroughly with water and air dried in shade and powdered using domestic grinder. Then Soxhlet extraction was done [10] using solvents acetone and distilled water. The extracts were further evaporated to a dry residue and then tested for various biological activities against the insect, Dysdercus cingulatus and the microbial organism, Pseudomonas aeruginosa

\section{Bioassay:}

\section{Nymphicidal Activity}

Nymphicidal effect was studied by using uniform sized, 12$24 \mathrm{hr}$ old 5 th stadium nymphs of $D$. cingulatus which were randomly selected from the stock culture. Ten insects were placed in a transparent plastic container and fed with cotton seeds soaked with four different concentrations of plant extracts. Control insects were maintained in another container and fed with distilled water soaked cotton seeds.

$1 \%, 5 \%, 10 \%$ acetone and aqueous extracts of the plant were dissolved in $10 \mathrm{ml}$ distilled water. Then the mixture was stirred well with glass rod. After this procedure, seeds of cotton were soaked and stirred well. The insects were allowed to feed for $96 \mathrm{hrs}$ for testing mortality. Four replicas were maintained for each concentration and mortality was recorded after 96hrs. Then the percentage mortality was calculated.

Percentage mortality $=\underline{\text { No. of dead larvae }} \times 100$ Total no. of larvae

\section{Fertility Test}

1day old adult females were selected from the normal culture. $10 \%$ stock solution of acetone and aqueous extracts of $B$. diffusa were prepared. From that $0.1 \mathrm{ml}$ were applied on the second tergite of the abdomen by using a micro syringe. Control insects were treated with distilled water. After 3 days, these females were released into transparent plastic jar and normal healthy males were released for mating. Four replicas were maintained for each concentration and observed the mating behavior and oviposition. Number of eggs laid by experimental insects was compared with control insects. Control experiment was also set up with normal untreated females and males.

\section{Repellent Activity}

For testing repellency [11], six $5^{\text {th }}$ stadium nymphs were randomly selected from the culture and kept in a petri dish which contained a Whatman's filter paper on the bottom. These petridishes were closed with transparent plastic sheet and made some small holes for aeration. After some time, different concentration $(5 \%, 10 \%)$ of acetone and aqueous extract of the plant $(0.5 \mathrm{ml})$ was injected into the filter paper in petridish slowly and observed the behavioral response of the insects. Four replicas were maintained for each concentration.

Percentage Repellency $=\underline{\text { No. of larvae repelled }} \times 100$ Total no. of larvae

\section{Ovicidal Effect}

30 numbers of newly laid eggs were collected and they were placed over cotton pads sprayed with plant extracts at different concentrations $(5 \%, 10 \%)$. Control eggs were maintained in cotton pads soaked with distilled water. Four replicas were maintained for each concentration and observed the hatchability and calculated the percentage mortality.

Percentage mortality $=$ No. of unhatched eggs $\times 100$

$$
\text { Total number of eggs }
$$

\section{Antimicrobial Test}

Pseudomonas aeruginosa was inoculated in Brain Heart Infusion Broth (BHIB) and compared the turbidity with that of the standard 0.5 McFarland solution. Mueller-Hinton Agar (MHA) plates were prepared for each experiment. The microbial lawn was prepared on agar plates by adjusted inoculums using a sterile cotton swab. Allowed to dry for 1-2 hrs and then an $8 \mathrm{~mm}$ biopsy bore was used to $<<$ punch out $>>, 3$ equally spaced wells on Mueller Hinton Agar plates. $200 \mu$ l of sample was then delivered to the wells. A positive control such as commercially available Chloramphenicol ${ }_{50}$ 
mcg disc was placed on the agar. Plates were then incubated for $18-24 \mathrm{hrs}$. All tests were performed in triplicate and inhibition zone were measured using a millimeter scale.

\section{RESULTS AND DISCUSSION}

\section{Nymphicidal activity}

Data regarding the effect of $B$. diffusa extracts on 5th instar nymph of $D$. cingulatus are summarized in Figure 5, 6. Significant level of mortality was observed on 5th instar nymphs in a dose dependant manner at $1 \%, 5 \%$ and $10 \%$ of acetone extracts (Figure 5) and aqueous extracts (Figure 6) of the plant. No significant degree of mortality was observed in control insects. After $96 \mathrm{hrs}$ of treatment, morphological and anatomical abnormalities were predominantly noticed at higher concentration of acetone and water extracts of the plant. It included incomplete moulting, shrunk abdomen, crumbled wings, feeding deterrence, and black shades on the body (Figure 1 and 2). Treated insects also showed malformed wings and died after moulting. Feeding deterrence was also showed at high doses of the plant extract.

\section{Repellent activity}

Repellent activity of randomly selected 5 th instar nymphs of D. cingulatus was found to be dose dependant. Acetone extracts showed more repellent activity at high dose compared with control insects. Aqueous extracts showed negligible average repellent activity (Table 1 ).

\section{Effect on reproduction}

Copulation period was shown to be prolonged between 2-3 days in the case of treated insects. The number of eggs laid by acetone treated insects were greatly reduced $(50-60$ eggs). Aqueous extracts also affected egg laying (60-65 eggs). Control insects laid 120- 150 eggs (Table 2). Topical application of the plant extract on newly emerged adult females showed low fecundity rate compared with control females.

\section{Ovicidal effect}

30 numbers of newly laid eggs were collected and they were placed over cotton pads sprayed with different dilutions of plants extracts. Control eggs were placed on cotton pads soaked in distilled water. Treated eggs turned pale brown and dead. Dried and shrunk eggs were observed in almost all experimental eggs. Few eggs hatched but the nymphs could not survive. In the case of control eggs $100 \%$ hatchability was observed (Table 3).

\section{Antimicrobial test}

The minimum inhibitory concentration and zone of inhibition values were carried out by using the bacterial strain $P$. aeruginosa. The minimum inhibitory concentration (MIC) and Zone of inhibition (ZOI) values were calculated with standard chloramphenicol ${ }_{50}$. From the results of MIC values, it indicates that $B$. diffusa showed significant antibacterial property against $P$. aeruginosa (Fig 3, 4). Table 4 indicated ZOI.

\section{Discussion}

Plants synthesize a number of secondary metabolites. Among them some of the compounds are recognized as insecticidal molecules. In the present study, the insecticidal effect of $B$. diffusa was tested on the insect $D$. cingulatus, the common red cotton bug. Antimicrobial activity was checked on $P$. aeruginosa. Four different concentrations 1\%, 5\%, 6\%, and $10 \%$ of acetone extract and aqueous extracts $5 \%, 10 \%$ and $20 \%$ concentration of the plant was tried against $D$. cingulatus $5^{\text {th }}$ stadium nymphs. Significant mortality was observed in dose dependent manner which demonstrates nymphicidal potential of the plant extract. The medicinal value of plants lies in some chemical substances that produce a definite physiological action on the body [12].

Dose dependent mortality due to extract of stem bark of Streblus asper [13] was reported for D. cingulatus. Extracts from the stem bark of Streblus asper possess insecticidal activity against the fifth instar of D. cingulatus. In 2012, Asha et al., [14] studied the biocidal activity of two marine green algae, Ulva fasciata Delile and Ulva lactuca Linnaeus against third instar nymph of $D$. cingulatus at different concentrations. Methanol extracts of both algae showed nymphicidal and anti ovipositional activity, reduced fecundity, hatchability, adult longevity and relative growth rate.

In 2010, Sahayaraj and Mahesh Tomson [15] studied the impact of two pathogenic fungal crude metabolites on mortality, biology and enzymes of D. cingulatus. Beauvaris bassiana (Balasmo) vuillimin and Metarhizium anisopliae (Metchnikoff) Sorokin crude metabolic extracts and fungal spores were tested against $D$. cingulatus under invitro conditions and both showed insecticidal properties. Antifeeding effect of varied concentration of Adathoda vasica and Vitex negundo crude methanolic leaf extracts was evaluated against $D$. cingulatus. $V$. negundo caused more nymphal deaths. Both plant extracts produced more than $50 \%$ nymphal mortality at two higher concentrations and $V$. negundo showed both antifeedant and nymphicidal activities [16].

Screening of insecticidal activity of brown macroalgal extracts against Dysdercus cingulatus were studied by [17]. The biocidal activity of hexane, chloroform, methanol and water extracts of brown algae, Sargassum wightii and Padina pavonica. The chloroform extract of $S$. wightii caused more nymphicidal effect at $96 \mathrm{hrs}$ than $P$. pavonica. In $P$. pavonica, mating period was highly prolonged by the aqueous extract. In the present study, the repellency and feeding deterrence were observed at different concentration. D. cingulatus nymph showed repellence on acetone extract of $B$. diffusa. 
Feeding deterrence was showed on high concentration of aqueous and acetone extract treated food. The results showed that the insects preferred untreated control food than any of the treated food. The compounds that prevent, block or otherwise interfere with food selection and consumption are referred to as feeding inhibitors. Antifeedants or feeding deterrents or phagodeterrents constitute a class of preingestive feeding inhibitors that act through gustatory receptors and evoke the rejection of plant material [18].

Repellency in the present study has been noted visually in the treated insects. $D$. cingulatus nymphs showed repellency in acetone extracts of $B$. diffusa treated areas on filter paper. Botanical pesticides generally have ovicidal and repellent activities. Repellents are the chemicals which cause an insect to make an oriented movement away from its source. Due to their odoriferous nature, oils of plants have been used for this purpose. D. cingulatus showed $95 \%$ repellency in Ailanthus excelsa extract of $\mathrm{n}$-Hexane, chloroform and methanol extracts [19].

Prabhu and John [20] studied on ovarian development in juvenilized adult $D$. cingulatus affected by some plant extracts. Topical application of different doses of acetone extracts of the plants Anthocephalus cadamba, Lantana camara, Tectona grandis, Calophyllum sp. and Phyllanthus emblica to the newly moulted last (5th) instar larvae resulted in $6^{\text {th }}$ instars retaining varying degrees of nymphal characters. However, there was a different extent of ovarian inhibition in some of these individuals. When such individuals were mated, their eggs developed normally. The adultoids in all cases produced normal eggs. The corpus allatum of the $6^{\text {th }}$ instar was only about half the size of that of the normal adult female, the size difference being statistically significant.

In 2010, Tanu Sharma and Ayesh Qamar et al., [21] studied on evaluation of neem extracts against the eggs and adults of Dysdercus cingulatus. The toxic efficiency of neem leaves, neem green seed coat, neem yellow seed coat and neem seed kernel were tested against $D$. cingulatus eggs and adults at different concentrations. Neem extracts showed highest mortality in low concentration and least mortality in yellow seed coat. Treated with the extracts noticed least survival of eggs.

Kitherian Sahayaraj and Mary Jeeva [22] in 2012 investigated the role of a brown seaweed alga, Sargassum tenerrimum against Dysdercus cingulatus. The impact of benzene $(\mathrm{BN})$, chloroform $(\mathrm{CH})$ and a mixture of benzene and chloroform $(\mathrm{BNCH})$ extracts, as well as two chromatographic fractions of $\mathrm{BNCH}$ (FR1 and FR2) were investigated for their insecticidal and ovipositional properties against $D$. cingulatus. The BN extracts showed the best insecticidal activity, higher than $\mathrm{BNCH}$ and $\mathrm{CH}$ extracts and all the extracts reduced the total nymphal developmental period of the pest in a dose dependent way. Adult longevity of both males and females was reduced by the $\mathrm{CH}$ and $\mathrm{BN}$ extracts. The $\mathrm{CH}$ extract reduced $D$. cingulatus oviposition, preoviposition and post-oviposition periods as well as fecundity. Females emerging from the BN category could not lay eggs. The BNCH fractions, FR1 and FR2, also exhibited nymphicidal activity against the pest. However, these fractions did not significantly alter the nymphal developmental period.

Evangelin et al., [11] demonstrated ovicidal, nymphicidal and juvenomimetic effect of Adathoda vasica extract on the red cotton stainer, D. cingulatus. The extract of $A$. vasica showed ovicidal, nymphicidal and juvenomimetic activity against this pest. Fertility and fecundity test were carried out by aqueous and acetone extract of $B$. diffusa in this study. The results showed that the extracts of $B$. diffusa affected the fertility and fecundity in D. cingulatus. The number of egg laid and percentage of hatching were significantly low. Aqueous extract of $B$. diffusa treated females showed prolonged copulation period and laid low number of eggs.

In the present study antibacterial property of aqueous extract of Boerhavia diffusa leaf was conducted by gram negative bacteria Pseudomonas aeruginosa. The extracts were tested by agar well diffusion method. A positive control Chloramphenico $1_{50} \mathrm{mcg}$ disc and negative control DMSO were used. The bacteria showed sensitivity to the plant extract. Phytochemicals present in the leaves of $B$. diffusa shows potent antibacterial activity against gram positive and gram-negative bacteria [23]. In 2008 Girish and Satish [24] observed that $B$. diffusa showed maximum inhibition on Staphylococcus aureus, Bacillus megaterium and Bacillus cereus at $50 \mu \mathrm{L}$ concentration. Mahesh et al, [25] reported that $B$. diffusa leaves have potential antibacterial activity against bacteria S. aureus, B.subtilis, S. faecalis, M. luteus, K. pneumoniae, $P$. vulgaris, $S$. marcescens and S. flexneri.

\section{CONCLUSION AND FUTURE SCOPE}

The present study obviously indicates the insecticidal as well as antimicrobial potential of the plant $B$. diffusa. Ovicidal, nymphicidal and repellent activity were exhibited against the serious cotton pest $D$. cingulatus. Antibacterial property of the plant was also demonstrated against the pathogenic strain of bacterium $P$. aeruginosa. Thus it can be concluded that this preliminary results may find significance in future research for developing a bioinsecticide as well as an antibacterial agent, thereby reducing the hazards of toxic chemicals. 


\section{Figures and Tables}

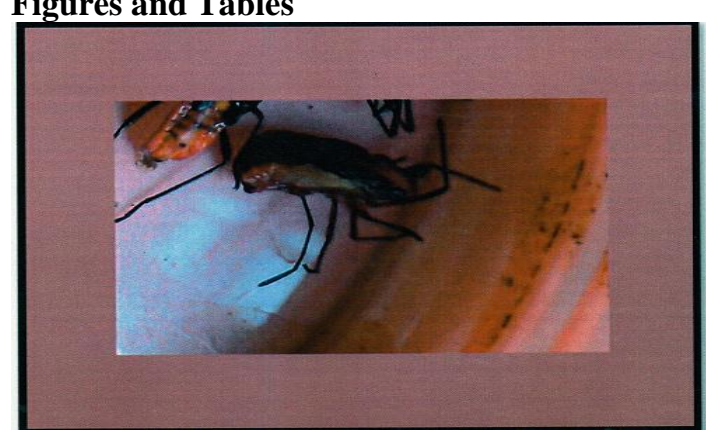

Figure 1: Incomplete Moulting 5th stadium nymphs of $D$. cingulatus

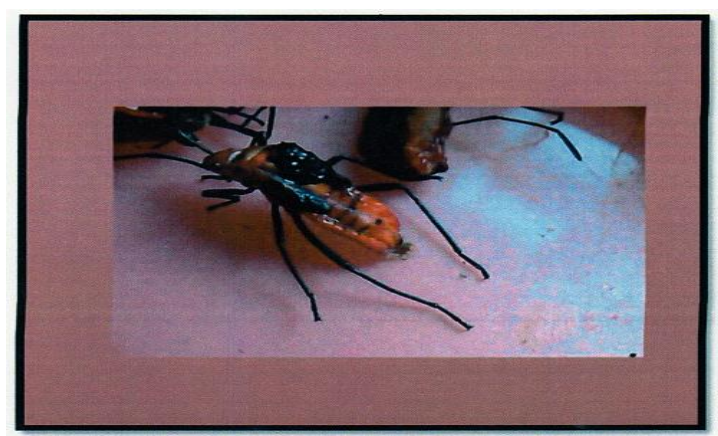

Figure 2: Shrunken Abdomen

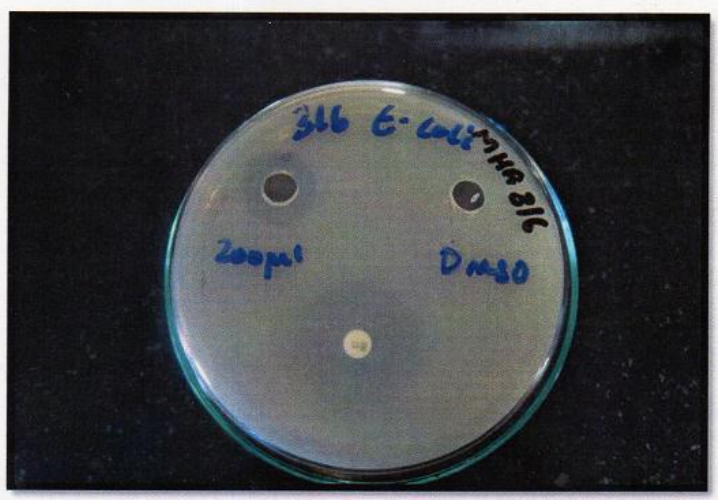

Figure 3: Antimicrobial effect of Boerhavia diffusa

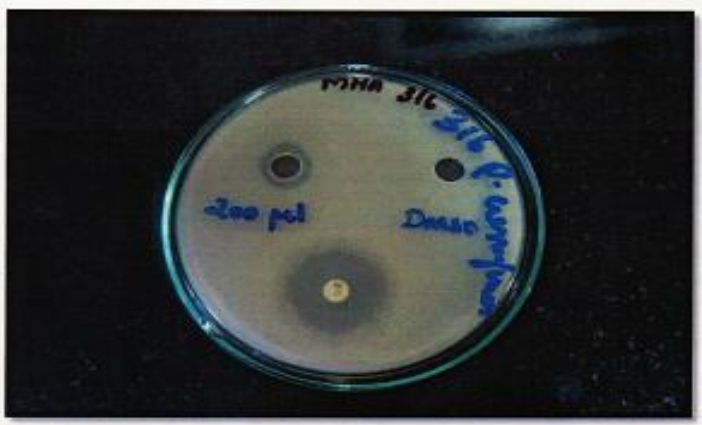

Figure 4: Antimicrobial effect of Boerhavia diffusa
Table 1: Repellent effect of acetone \& aqueous extract of Boerhavia diffusa on Dysdercus cingulatus

\begin{tabular}{|l|l|c|}
\hline Plant & $\begin{array}{c}\text { Dose } \\
(\mathbf{1 0 0} \boldsymbol{\mu l})\end{array}$ & No. of eggs laid \\
\hline Boerhavia diffusa & Acetone extract & $50-60$ \\
\hline & Aqueous extract & $60-65$ \\
\hline
\end{tabular}

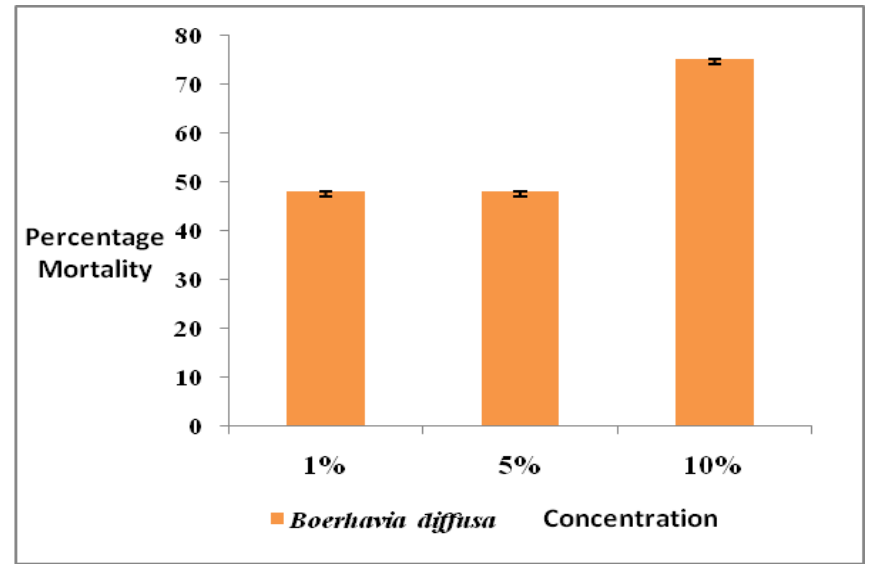

Each value is Mean \pm S.D, $n=4$.

Each value is significant at $\mathrm{p} \leq 0.05$

Figure 5: Effect of Boerhavia diffusa acetone extracts on $5^{\text {th }}$ nymph of Dysdercus cingulatus

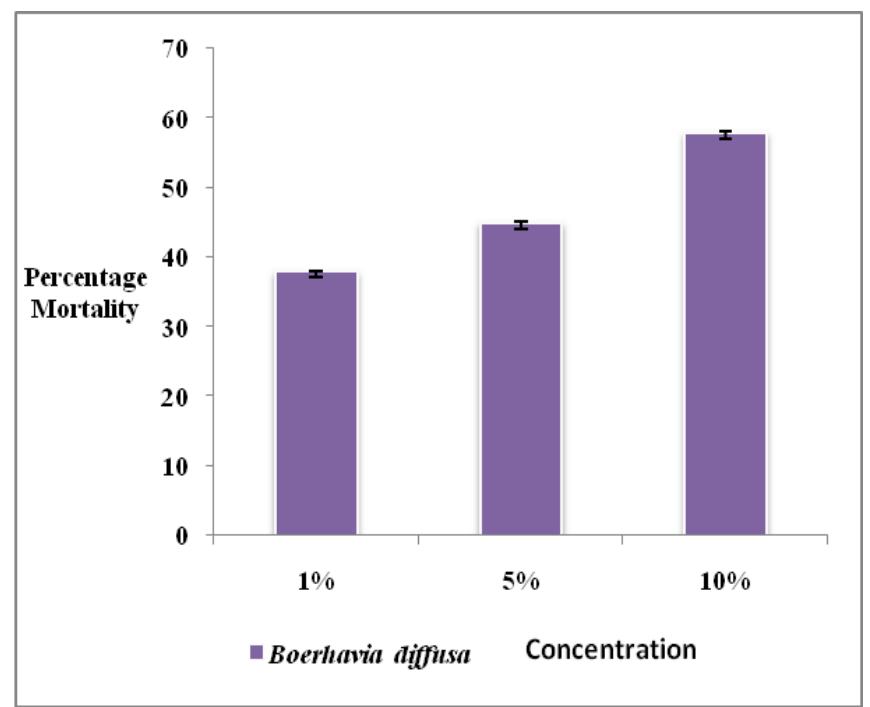

Each value is Mean \pm S.D, $n=4$.

Each value is significant at $p \leq 0.05$

Figure 6: Effect of Boerhavia diffusa aqueous extracts on $5^{\text {th }}$ nymph of Dysdercus cingulatus 
Table 2: Effect of Acetone and Aqueous extract of Boerhavia diffusa on Fecundity rate of Dysdercus cingulatus

\begin{tabular}{|l|c|l|l|}
\hline \multirow{2}{*}{} & \multirow{2}{*}{\begin{tabular}{c} 
Concentration \\
\cline { 3 - 4 }
\end{tabular}} & \multicolumn{2}{|c|}{ Percentage Repellency } \\
\cline { 2 - 4 } & $\%$ & $\begin{array}{l}\text { Acetone } \\
\text { extract }\end{array}$ & $\begin{array}{l}\text { Aqueous } \\
\text { extract }\end{array}$ \\
\hline $\begin{array}{l}\text { Boerhavia } \\
\text { diffusa }\end{array}$ & 5 & 7.33 & 0.33 \\
\cline { 2 - 4 } & 10 & 9.33 & 0.66 \\
\hline Control & - & 0 & 0 \\
\hline
\end{tabular}

Table 3: Ovicidal effect of acetone $\&$ aqueous extract of Boerhavia diffusa on Dysdercus cingulatus

\begin{tabular}{|l|l|c|}
\hline \multirow{2}{*}{ Concentration } & \multicolumn{2}{|c|}{ Percentage Mortality } \\
\cline { 2 - 3 } & Acetone extract & Aqueous extract \\
\hline $\mathbf{5 \%}$ & 86.6 & 7.3 \\
\hline $\mathbf{1 0 \%}$ & 93.3 & 83.3 \\
\hline Control & 0 & 3.3 \\
\hline
\end{tabular}

Table 4: Effect of antimicrobial activity of Boerhavia diffusa

\begin{tabular}{|c|c|c|c|c|}
\hline $\begin{array}{l}\text { Sl. } \\
\text { No. }\end{array}$ & Parameters & $\begin{array}{l}\text { Test } \\
\text { Method }\end{array}$ & $\begin{array}{l}\text { Sample } \\
\text { Volume }\end{array}$ & $\begin{array}{l}\text { Test } \\
\text { Result }\end{array}$ \\
\hline 1 & $\begin{array}{l}\text { Sample } \\
\text { concentration } \\
\text { - } 500 \text { ppm }\end{array}$ & & & \\
\hline 2 & E. coli & $\begin{array}{l}\text { agar well } \\
\text { diffusion }\end{array}$ & 200ul & $\mathrm{S}-17 \mathrm{~mm}$ \\
\hline 3 & P. aeruginosa & $\begin{array}{l}\text { Agar } \\
\text { well } \\
\text { diffusion }\end{array}$ & 200ul & $\mathrm{S}-13 \mathrm{~mm}$ \\
\hline
\end{tabular}

*S-Sensitive

\section{ACKNOWLEDGMENT}

We express our sincere gratitude to the University of Kerala, Thiruvananthapuram, India for financial assistance under Junior Research Fellowship.

\section{REFERENCES}

[1]. S. Ignacimuthu, "Insect Pest Control: Using Plant Resources". Alpha Science International: 1.1, 2012.
[2]. D.E. Djeussi., J.A.K Noumedem., J.A Seukep, A.G. Fankam, I.K. Voukeng., S.B. Tanken., A.H.L. Nkuete, V. Kuete, "Antibacterial activity of selected edible plants extracts against multi drug- resistant Gram-negative bacteria", BMC Complementary and Alternative Medicine, Vol.13, pp.164, 2013.

[3]. S. Singh, S. Singh, "Economic evaluation of pest management technologies for sustainable crop production in Punjab", Agricultural Economics Research Review, Vol. 20, pp. 77-86, 2007.

[4]. Minfal, "Agricultural Statistics of Pakistan; Cash crops", Government of Pakistan, Ministry of Food, Agricultural and Livest. (Econ. Wing), Islamabad: pp. 29-30, 2008.

[5]. Balcht, Aldona, Smith, Raymand, "Pseudomonas aeruginosa: Infections and Treatment", Informa Health care, pp. 83-84, 1994.

[6]. K. Poole, "Efflux-mediated multiresistance in Gram-negative bacteria", Clinical Microbiology and Infection, DOI: http://dx.doi.org/10.1111/j.1469-0691.2004.00763.x, 2004.

[7]. L.P. Awasthi, H.N. Verma, "Boerhavia diffusa - a wild herb with potent biological and antimicrobial properties", Asian AgriHistory, Vol. 10, pp. 55-68, 2006.

[8]. Babita Agarwal, Sunanda Das, Archana Pandey, "Boerhavia diffusa Linn: A Review on its Phytochemical and Pharmacological Profile", Asian Journal of Applied Sciences, Vol. 4, Issue. 7, pp. 663-684, 2011.

[9]. D. Krishnaiah, A. Devi, Bono, R. Sarbatly, "Studies on phytochemical constituents of six Malaysian medicinal plants", Journal of Medicinal Plants Research, Vol. 3, pp. 67-72, 2009.

[10]. Harborne J.B., "Phytochemical Methods- A guide to modern techniques of plant analysis", Chapman \& Hall publications, London, $3^{\text {rd }}$ ed. 1998.

[11]. G. Evangelin, Chris Vaz., Junas Ekka., John Juliet, S.J. J. William, "Ovicidal, nymphicidal and juvenomimetic effect of Adathoda vasica extract on the red cotton stainer, Dysdercus cingulatus". International Journal of Humanities, Arts, Medicinal and Sciences, Vol. 2, Issue.1, pp. 49-56, 2014.

[12]. P. Ramesh, A. Subramani, "Effect of antimicrobial activity of Eupatorium odoratum against clinical microbes" Journal of Scientific Research in Biological Sciences, Vol.5, Issue.5, pp.30-35,2018.

[13]. M.S. Hashim, K.S. Devi, "Insecticidal actions of the polyphenolic rich fractions from the stem bark of Streblus asper on Dysdercus cingulatus", Fitoterapia, 744: pp. 670-676, 2003.

[14]. A. Asha, J. M. Rathi, D. Patric Raja, K. Sahayaraj, "Biocidal activity of two marine green algal extracts against third instar nymph of Dysdercus cingulatus (Fab.) (Hemiptera: Pyrrhocoridae)", Journal of Biopesticides, Vol. 5 (Supplementary), pp. 129-134, 2012.

[15]. K. Sahayaraj, Mahesh Tomson, "Impact of two pathogenic fungal crude metabolites on mortality biology and enzymes of Dysdercus cingulatus" Journal of Biopesticides, Vol. 3 (1), (special issue), pp. 163-167, 2010.

[16].P. Ranilalitha, M. Sukumaran, S. Raveendran, Kavitha Amirthanayagi, "Evalution of nymphicidal effect of two indigenous plant extracts on cotton pest, Dysdercus cingulatus", International Journal of Pure and Applied Zoology, Vol. 3(1), pp. 24-30, 2015.

[17]. A. Asaraja, K. Sahayaraj, "Screening of insecticidal activity of brown macroalgal extracts against Dysdercus cingulatus (Fab.) (Hemiptera: Pyrrhocoridae)", Journal of Biopesticides, Vol. 6(2), pp. 193-203, 2013.

[18]. S. J. Boeke, I. R. Baumgart, I. J. Van Loon, A. Dicke, M. Van Husin, D. K. Kossou, "Toxicity and repellency of African plants traditionally used for the protection of stored cowpea against Callosobruchus maculates", Journal of Stored Products Research, Vol. 40, pp. 423-438, 2004. 
[19]. Harshalata Sontakke, Irshad Baba, S. M. Jain, R. C. Saxena, Mahesh Ningwal, "Effect of extracts of Ailanthus excelsa on red cotton bug (Dysdercus cingulatus)", IOSR Journal of Pharmacy and Biological Sciences, Vol. 6(5), pp. 44-45, 2013.

[20]. V. K. K. Prabhu, M. John, "Ovarian development in juvenilised adult Dysdercus cingulatus affected by some plant extracts", DOI:10.1111/j.1570-7458.1975.tb00389. X, 2011.

[21]. Tanu Sharma, Ayesha Qamar, Absar Mustafe Khan, "Evaluation of neem (Azadirachta indica) extracts against the eggs and adults of Dysdercus cingulatus (Fab.)", World Applied Sciences Journal, Vol. 9(4), pp. 398-402, 2010.

[22]. K. Sahayaraj, Y.M. Jeeva, "Nymphicidal and ovicidal efficacy of seaweed Sargassum tenerrium (J. Agardh) against Dysdercus cingulatus (Fab.) (Pyrrhocoridae)", Chilean Journal of Agriculture Research, Vol. 72, Issue. 1, pp.152-156, 2012.

[23]. A.R. Mahesh, Harish kumar, M.K. Rangamani, Raviraj Anand Devkar, "Detailed study on Boerhavia diffusa Plant for its Medicinal Importance - A Review", Research Journal of Pharmaceutical Sciences, Vol. 3 Issue. 1, pp. 28-36, 2012.

[24]. H.V. Girish, S. Sathish, "Antibacterial activity of important medicinal plants on human pathogenic bacteria -A comparative analysis", World Applied Science, Vol. 5, pp. 267-271, 2008.

[25]. A.R. Mahesh, M. K. Rangamani, D. R. Harish kumar, "Enrichment of Flavonoids from the methanolic extracts of Boerhavia diffusa Roots by Partitioning technique", Research Journal of Chemistry Sciences, Vol. 3, Issue.1, pp. 43-47, 2013.

\section{AUTHORS PROFILE}

Manjima T.M, done her M.Phil. programme in Pest Management, Department of Zoology, University College, Thiruvananthapuram, Kerala, India. Now she is working as teacher.

Indusree O.G, currently doing her Ph.D. programme in Vector Biology, Department of Zoology, University College, Thiruvananthapuram, Kerala, India.

Dr. Ajitha V.S. awarded her M.Phil., Ph.D. and Post Doctorate in Zoology. She is currently working as Assistant Professor of Zoology, University College, Thiruvananthapuram; Kerala. She joined teaching profession in 2010. She published more than 13 research papers in reputed International and National journals and now doing research on insect pests and vectors. She has 13 years of research experience and has four research scholars working under her supervision. 